\title{
Effect of $\beta$-lactoglobulin A and B whey protein variants on cheese yield potential of a model milk system
}

\author{
M. A. Meza-Nieto, ${ }^{\dagger} \dagger$ A. F. González-Córdova, ${ }^{*}$ J. Piloni-Martini, $†$ and B. Vallejo-Cordoba*1 \\ *Laboratorio de Química y Biotecnología de Productos Lácteos Centro de Investigación en Alimentación y Desarrollo, A.C, \\ Apartado 1735 Hermosillo, Sonora 83000, Mexico \\ †Instituto de Ciencias Agropecuarias, Universidad Autónoma del Estado de Hidalgo, Abasolo 600, Pachuca Hidalgo 43000, Mexico
}

\section{ABSTRACT}

Cheese yield mainly depends on the amount and proportion of milk constituents; however, genetic variants of the proteins present in milk may also have an important effect. The objective of this research was to study the effect of the variants $\mathrm{A}$ and $\mathrm{B}$ of $\beta$-lactoglobulin (LG) on cheese yield using a model system consisting of skim milk powder fortified with different levels of a mixture containing $\alpha$-lactalbumin and $\beta$-LG genetic variants $(\mathrm{A}, \mathrm{B}$, or $\mathrm{A}-\mathrm{B})$ in a 1:2 ratio. Fortified milk samples were subjected to pasteurization at $65^{\circ} \mathrm{C}$ for 30 min. Miniature cheeses were made by acidifying $(\mathrm{pH}=$ 5.9) fortified milk and incubating with rennet for $1 \mathrm{~h}$ at $32^{\circ} \mathrm{C}$. The clot formed was cut, centrifuged at $2,600 \times g$ for 30 min at $20^{\circ} \mathrm{C}$ and drained for determining cheese yield. Cheese-yielding capacity was expressed as actual yield (grams of cheese curd per $100 \mathrm{~g}$ of milk) and dry weight yield (grams of dried cheese curd per $100 \mathrm{~g}$ of milk). Free-zone capillary electrophoresis was used for determining $\beta$-LG A or B recovery in the curd during rennet-induced coagulation. The presence of $\beta-\mathrm{LG}$ variant $\mathrm{B}$ resulted in a significantly higher actual and dried weight cheese yield than when A or A-B were present at levels $\leq 0.675 \%$ of whey protein (WP) addition. Results of free-zone capillary electrophoresis allowed us to infer that $\beta$-LG B associates with the casein micelles during renneting, as shown by an increase in the recovery of this variant in the curd when $\beta$-LG B was added up to a maximum at $0.45 \%$ (equivalent to $0.675 \% \mathrm{WP}$ ). In general, actual or dried weight cheese yield increased as WP addition was increased from 0.225 to $0.675 \%$. However, when WP addition ranged from 0.675 to $0.90 \%$, a drastic drop in cheese yield was observed. This behavior may be because an increase in the aggregation of casein micelles with a concomitant inclusion of whey protein in the gel occurs at low levels of WP addition, whereas once the association of WP with the casein micelles reach a saturation point at addition levels higher

Received July 19, 2012.

Accepted May 2, 2013.

${ }^{1}$ Corresponding author: vallejo@ciad.mx than $0.675 \%$, rearrangements of the gel network result in larger whey expulsion and syneresis. This knowledge is expected to be useful to maximize cheese yield and optimize processing conditions during cheese and cheese analogs manufacturing.

Key words: $\beta$-lactoglobulin whey protein variant, cheese yield, capillary electrophoresis

\section{INTRODUCTION}

Cheese yield is important for the profitability of a cheese plant, as it reflects the amount of cheese made from a given amount of milk. Therefore, much interest has been observed toward genetic variants of milk proteins, as they might influence cheese yield (Celik, 2003). Although several studies have reported on some association between genetic variants and cheese yield, most have failed to correct for factors such as milk composition, which has a profound effect on cheese yield (Choi and Ng-Kwai-Hang, 2002; Ng-Kwai-Hang and Grosclaude, 2002).

In general, milk protein $(\alpha-\mathrm{CN}, \beta-\mathrm{CN}, \kappa-\mathrm{CN}$, and $\beta-\mathrm{LG}$ ) genetic variants influence cheese-yielding capacity, coagulation properties, and composition of milk, but this effect is mainly attributed to milk protein, milk fat, or milk solid content (Celik, 2003). Thus, it was reported that the $\beta$-LG B variant was associated with higher fat (Aleandri et al., 1990), protein (NgKwai-Hang et al., 1984), CN (Ng-Kwai-Hang et al., 1986; Bonfatti et al., 2010), CN number (Hallén et al., 2008), total solids content (McLean et al., 1984), and increased cheese yield (Schaar et al., 1985; Marziali and Ng-Kwai-Hang, 1986; Aleandri et al., 1990; Choi, 1996). Furthermore, Tong et al. (1993) and Andrén (2007) suggested that milk containing $\beta-L G$ B was more suited for cheese-making, as it produced a firmer curd than milk containing the A variant. On the contrary, others reported an association of $\beta-\mathrm{LG}$ A with shorter rennet clotting time and highest curd firmness (Marziali and Ng-Kwai-Hang, 1986; Choi, 1996; Glantz et al., 2011), whereas others could not find any relation with $\beta$-LG variants (Aaltonen and Antila, 1987; Pagnacco and Caroli, 1987; Lodes et al., 1996; Celik, 2003). 
Therefore, differences in the technological properties of milk due to certain genetic variants have to be confirmed by studies comparing isolated and pure forms of the individual milk proteins without the confounding effects of other milk components (Ng-Kwai-Hang, 1998). Thus, the aim of this work was to investigate the effect of mixing isolated and purified $\beta-\mathrm{LG} \mathrm{A}$ or $\mathrm{B}$ with $\alpha$-LA and $\mathrm{CN}$ on cheese yield and syneresis in a miniature cheese model system. In addition, including higher levels of whey protein (WP) content than that present in milk (approximately 0.30\%), may help to gain some insight in the effect of WP addition in cheese analogs manufacturing.

\section{MATERIALS AND METHODS}

\section{Materials and Reagents}

Analytical grade reagents and standards of $\beta$-LG A and $\mathrm{B}$ variants and $\alpha-\mathrm{LA}$ were from Sigma Chemical Co. (St. Louis, MO) and Chymosin was from Chr. Hansen A/S (Hørsholm, Denmark). Low-heat skim milk powder was used in all the experiments. Milli-Q water was used throughout unless otherwise stated. Purified $\beta-\mathrm{LG}$ and $\alpha$-LA were prepared as described by the separation and precipitation method of Mailliart and Ribadeau-Dumas (1988).

\section{Samples}

Mixed CN or whey renneting systems were prepared as described by Meza-Nieto et al. (2007). Briefly, milk powder solutions were made at $10 \%$ (wt/wt) and the necessary amount of WP were added so as to yield $0.225,0.450,0.675,0.900$, and $1.35 \%$ (wt/wt), $\beta$-LG concentrations of $0.15,0.30,0.45,0.60$, or $0.90 \%$ (wt/ wt), and $\alpha$-LA concentrations of $0.075,0.150,0.225$, 0.300 , or $0.450 \%$ (wt/wt; i.e., the $\alpha$-LA to $\beta$-LG ratio was kept at $1: 2$ ) of $\mathrm{A}, \mathrm{B}$, or a mixture (1:1) of $\mathrm{A}$ and $\mathrm{B}$ variants. These will be designated as $\beta$-LG A, $\beta$-LG $\mathrm{B}$, and $\beta-\mathrm{LG} \mathrm{A}-\mathrm{B}$, respectively. Mixed systems (10 $\mathrm{mL})$ were equilibrated $\left(25^{\circ} \mathrm{C}, 1 \mathrm{~h}\right)$, pasteurized $\left(65^{\circ} \mathrm{C}\right.$ for $30 \mathrm{~min}$ ) under continuous stirring in a thermostatcontrolled water bath, cooled by immersion in ice water to below $10^{\circ} \mathrm{C}$, and held at that level for $2 \mathrm{~min}$.

\section{Miniature Cheese Making Procedure}

Miniature cheese model systems were prepared following the procedure reported by Melilli et al. (2002), with modifications. Samples $(10 \mathrm{~mL})$ were transferred to centrifuge tubes and $\mathrm{pH}$ was adjusted to 5.9 with acetic acid $(9 \% \mathrm{vol} / \mathrm{vol})$. Then, samples were heated until they reached $32^{\circ} \mathrm{C}$ and an aliquot of rennet $(0.15$ $\mathrm{mL} / \mathrm{L}$; equivalent to 90 international milk-clotting units) was added and incubated for $1 \mathrm{~h}$. At the end of incubation, all samples formed a firm coagulum. Then, tubes were centrifuged at $20^{\circ} \mathrm{C}$ for $30 \mathrm{~min}$ at $2,600 \times$ g. After $30 \mathrm{~min}$, the tubes were carefully removed from the centrifuge; each tube contained a curd pellet and a clear whey supernatant. Then, whey from each centrifuge tube was decanted from the pellet left in the bottom of the tube, collected, and weighed.

\section{Cheese Yield}

Two different methods were used to express cheeseyielding capacity for each batch of individual sample mixture used in cheese making: (1) actual yield, which is grams of cheese curd per $100 \mathrm{~g}$ of milk; and (2) dry weight yield, which is grams of dry cheese curd per $100 \mathrm{~g}$ of milk (Melilli et al., 2002). Using a metal spatula, curds were quantitatively transferred into predried and cooled aluminum weighing dishes for the determination of actual yield. Two empty predried pans were weighed as blanks. For dry weight yield determination, pans with curds and blanks were dried at $100^{\circ} \mathrm{C}$ for $4 \mathrm{~h}$ in a forced-air drying oven (VWR, Sheldon Manufacturing Inc., Cornelius, OR). After $4 \mathrm{~h}$, the pans were removed from the oven and cooled in a desiccator to room temperature and weighed.

\section{Free-Zone Capillary Electrophoresis}

$\beta$-Lactoglobulin A or B content in miniature cheeses were determined using the free-zone capillary electrophoresis method described by Olguin-Arredondo and Vallejo-Córdoba (1999). Briefly, separations were carried out using an HP 3D Capillary Electrophoresis System (Hewlett-Packard, Waldbronn, Germany) in an uncoated fused silica capillary $(72 \mathrm{~cm} \times 50 \mu \mathrm{m}$ i.d. $)$ maintained at $40^{\circ} \mathrm{C}$. Injection was carried out using $\mathrm{N}_{2}$ pressure $(50$ mbar) for $10 \mathrm{~s}$. The separation was carried out at $25 \mathrm{kV}$ in $0.05 \mathrm{M}$ of borate buffer containing Tween 20 (0.1\%; Sigma Chemical Co.) at pH 8.0, and detection took place at $214 \mathrm{~nm}$. Samples $(25 \mathrm{mg})$ were prepared by resuspending freeze-dried miniature cheeses in distilled deionized water $(0.5 \mathrm{~mL})$. Then, 2 $\mathrm{mL}$ of borate buffer solution were added and samples were centrifuged at $3,000 \times g\left(15 \mathrm{~min}\right.$ at $\left.20^{\circ} \mathrm{C}\right)$. Aliquot samples of the supernatant were subjected to capillary electrophoresis.

\section{Statistical Analysis}

All experiments were performed in triplicate. ANOVA was applied to determine the effects of $\beta$-LG variants and WP added to milk on cheese-yielding capacity of model systems. Means were tested by Tukey's pairwise comparisons at a $95 \%$ confidence level. 


\section{RESULTS AND DISCUSSION}

This study aimed to investigate cheese-yielding capacity of rennet-induced coagulation behavior of mixtures of skim milk powder with $\beta$-LG A or $\beta$-LG B WP variants in isolation or with a physical mixture of both ( $\beta$-LG A-B) in the presence of $\alpha-\mathrm{LA}$ at a fixed $\beta-\mathrm{LG}$ to $\alpha$-LA ratio. Thus, it was of great interest to study the effect of $\beta-\mathrm{LG} \mathrm{A}$ or $\mathrm{B}$ variants at different concentrations on cheese-yielding capacity in a miniature cheese model. Figure 1 shows actual cheese yield, which is grams of cheese curd per $100 \mathrm{~g}$ of milk, as WP addition is increased. The presence of variant $\mathrm{B}$ of $\beta-\mathrm{LG}$ showed a significantly higher actual cheese yield $(P \leq$ $0.05)$ compared to when A or A-B variants were present when WP was up to $0.675 \%$. Actual cheese yield was 1.3 or $2.3 \%$ higher when $\beta$-LG B was present compared to when variants $\mathrm{A}$ or $\mathrm{AB}$ were present at $0.675 \%$ of WP addition. Then, a drastic drop was observed at $0.9 \%$, with a marginal recovery at $1.35 \%$ when $\beta$-LG A or B were present.

Conversely, dry weight yield was significantly $(P \leq$ $0.05)$ higher when $\beta$-LG $\mathrm{B}$ was present compared to when $\mathrm{A}$ or $\mathrm{AB}$ were present at all levels of WP addition (Figure 2). Dry weight cheese yield was 0.32 or $0.42 \%$ higher when $\beta$-LG B was present compared to when variants $\mathrm{A}$ or $\mathrm{AB}$ were present at $0.675 \%$ of $\mathrm{WP}$ addition. Similarly, highest recoveries of total solids in cheese were observed for the presence of phenotype $\mathrm{BB}$ compared to when $\mathrm{AB}$ was present in milk (Choi and Ng-Kwai-Hang, 2002). Dry weight cheese yield

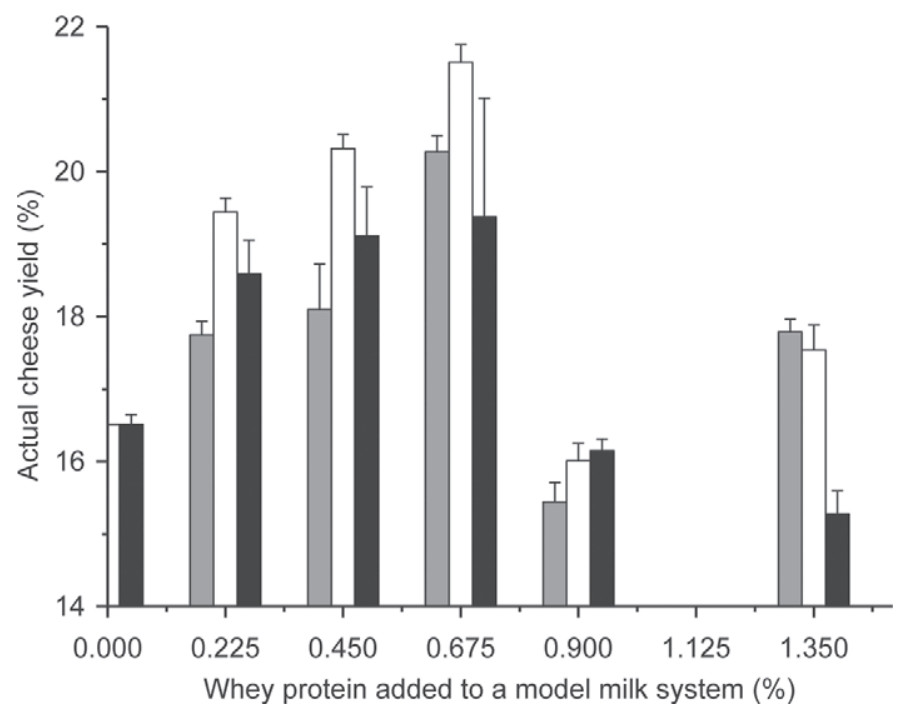

Figure 1. Actual cheese yield of miniature model cheese as a function of whey protein addition $(\mathrm{n}=3)$. Model cheese containing $\beta$-LG B (white bars), $\beta$-LG A (gray bars), and $\beta$-LG A-B (black bars). Error bars represent the SD.

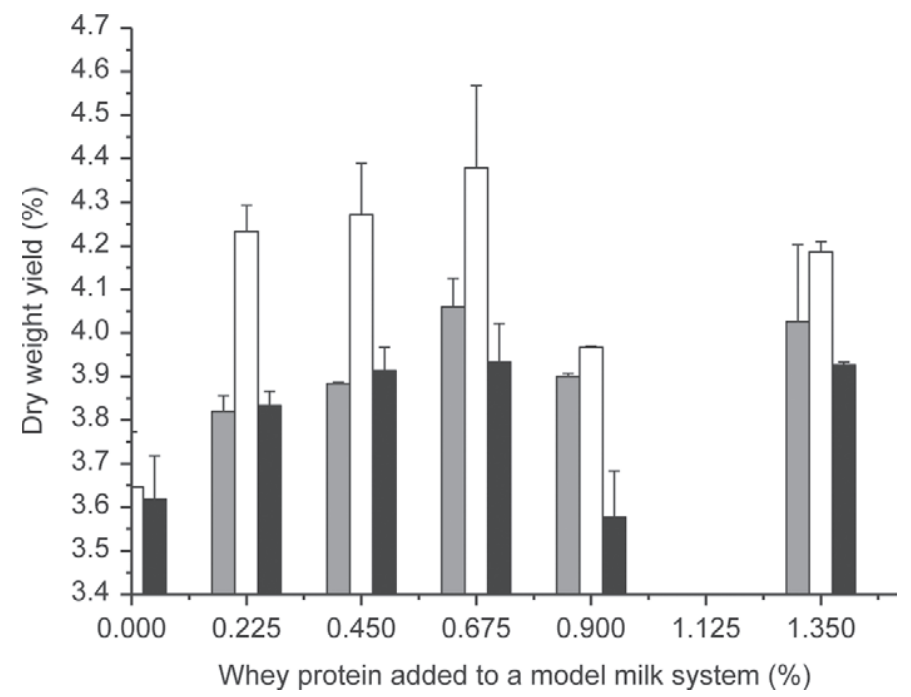

Figure 2. Dry weight cheese yield of miniature model cheese as a function of whey protein addition $(\mathrm{n}=3)$. Model cheese containing $\beta$-LG B (white bars), $\beta$-LG A (gray bars), and $\beta$-LG A-B (black bars). Error bars represent the SD.

increased as WP increased up to $0.675 \%$, dropped considerably at $0.90 \%$, and recovered marginally at $1.35 \%$.

Although the primary factor influencing cheese yield is given by milk composition, the kinetics during the coagulation of milk is also a determining factor (Vasbinder et al., 2003). To this end, the variation in actual and dry weight cheese yield with WP addition (Figures 1 and 2) revealed that 3 domains of behavior seem to operate in the miniature cheese model systems. At low levels of WP addition $(\leq 0.675 \%)$, an increase occurs in the aggregation of $\mathrm{CN}$ micelles with concomitant inclusion of WP in the gel, resulting in higher cheese yield (Figures 1 and 2). However, the association of WP with the $\mathrm{CN}$ micelles seems to reach a saturation point so that addition levels higher than $0.675 \%$ seem to interpose a steric hindrance, either in the primary stage of coagulation, preventing the action of rennet on $\mathrm{CN}$ micelles, or in the secondary phase during the aggregation of micelles. Thus, a drastic reduction in cheese yield at $0.9 \%$ WP was observed (Figures 1 and 2). Furthermore, with $1.35 \%$ of WP, cheese yield increased slightly when $\beta$-LG A or B were present (Figures 1 and 2), and this could be due to a destabilization of the $\mathrm{CN}$ micelles or self-association of $\mathrm{CN}$ due to exclusion effects between WP and CN micelles caused by an excess of WP.

Figure 3 shows the amount of $\beta-\mathrm{LG}$ A or B recovered in miniature cheeses as determined by capillary electrophoresis. An increase in the recovery of this variant in the curd when $\beta-\mathrm{LG} B$ was added up to a maximum at $0.45 \%$ (equivalent to $0.675 \%$ of $\mathrm{WP}$ addition) allowed us to infer that $\beta$-LG B associates with the $\mathrm{CN}$ micelles during renneting (Figure 3). Maximum $\beta$-LG B recovered in the curd at $0.675 \% \mathrm{WP}$ 
addition also corresponded to the highest cheese yield obtained in the miniature cheese model (Figures 1 and 2 ). This point may represent the most aggregation of $\mathrm{CN}$ micelles with concomitant inclusion of WP in the gel. Conversely, $\beta$-LG A did not seem to associate with the $\mathrm{CN}$ micelles during renneting, as recovered $\beta$-LG in the curd was significantly $(P \leq 0.05)$ lower (Figure $3)$. Increased cheese yield when the variant B of $\beta$-LG was present could be partly due to the physicochemical differences between variants $\mathrm{A}$ and $\mathrm{B}$. The lower charge density in $\beta$-LG B species than in $\beta$-LG A may account for the ease of the former to associate with the CN micelle surface, as the result of lower electrostatic repulsion expected. These results are consistent with the report that $\beta$-LG A does not associate with the CN micelles even before renneting regardless of heat treatment $\left(65^{\circ} \mathrm{C}, 30 \mathrm{~min}\right.$; Meza-Nieto et al., 2007).

The kinetics of gel formation in these rennet-induced gels with different levels of $\beta$-LG variants was addressed in a previous study by using small deformation-sensitive rheology (Meza-Nieto et al., 2007). The preferential effect of $\beta$-LG $\mathrm{B}$ over $\mathrm{A}$ on the mechanical strength of the gels was shown and may be due to the formation of cross-links and aggregates involving WP and rennet hydrolysis products or an increase in the size of the CN micelles caused by the grafting of $\beta$-LG B to its surface, or both (Meza-Nieto et al., 2007). Also, the critical gel time was slightly shorter for $\beta$-LG B than for $\beta$-LG $\mathrm{A}$, and the variation in the critical gel time with the concentration of WP also revealed 3 domains of behavior (Meza-Nieto et al., 2007) that coincided

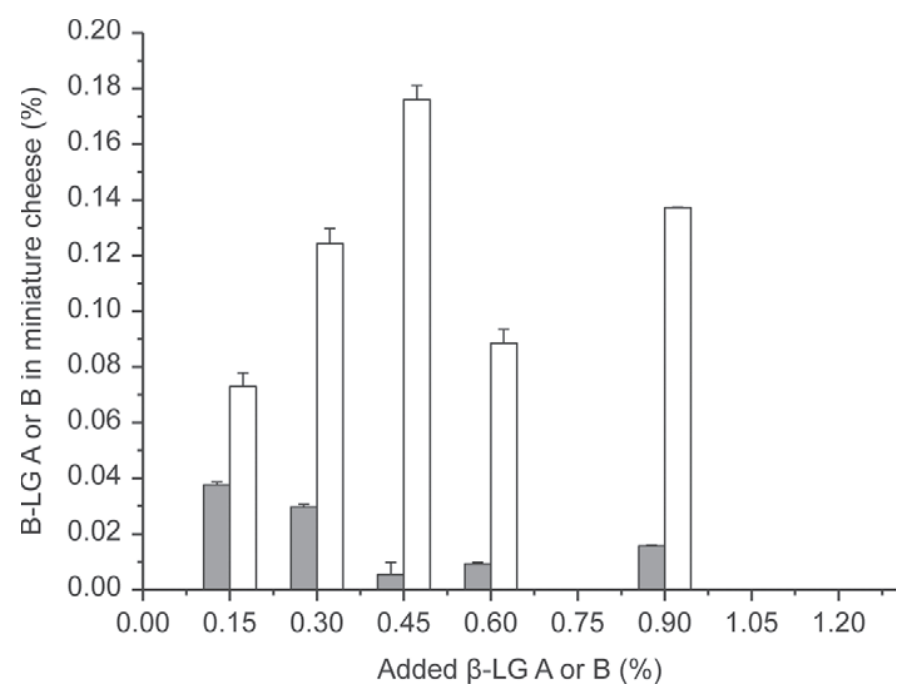

Figure 3. $\beta$-Lactoglobulin A or B content in miniature model cheese as a function of whey protein addition $[0.225,0.450,0.675$, 0.900 , and $1.35 \%$ (wt/wt) correspond to $\beta-\mathrm{LG}$ concentrations of 0.15 , $0.30,0.45,0.60$, and $0.90 \%$ (wt/wt); $\mathrm{n}=3$ ]. Model cheese containing $\beta$-LG B (white bars) and $\beta$-LG A (gray bars). Error bars represent the SD. with the 3 domains observed for the cheese-yielding capacity reported in the present study.

Several studies have addressed the type of interactions between $\beta$-LG and CN micelles, and it was clearly established that $\beta-\mathrm{LG}$ and $\kappa-\mathrm{CN}$ form a heat-induced complex via thiol or disulfide exchange reaction and hydrophobic interactions in model systems as well as in milk (Reddy and Kinsella, 1990; Law et al., 1994; Corredig and Dalgleish, 1999). At low temperatures, of approximately $70^{\circ} \mathrm{C}$, hydrophobic bonding is principally responsible for the complex formation between $\beta$-LG and $\kappa-\mathrm{CN}$, and, at higher temperatures, the sulfhydryl-disulfide interchange reactions are involved (Jan and Swaisgood, 1990). As the model milk system in this study was subjected to low temperatures $\left(65^{\circ} \mathrm{C}\right.$, $30 \mathrm{~min}$ ) before renneting, it is most likely that the type of interactions between $\beta-\mathrm{LG}$ and $\mathrm{CN}$ micelles were of hydrophobic nature.

Figure 4 shows the amount of serum recovered from cheese-making as a function of WP addition; syneresis decreased with WP addition, achieving its lowest level at $0.675 \%$ when maximum cheese yield was also obtained. However, syneresis dramatically increased at $0.90 \%$ of WP addition, with a marginal drop at $1.35 \%$. Again, this behavior may be because an increase in the aggregation of $\mathrm{CN}$ micelles with a concomitant inclusion of WP in the gel occurs at low levels of WP addition, whereas, once the association of WP with the CN micelles seem to reach a saturation point at addition levels higher than $0.675 \%$, rearrangements of the gel network result in larger whey expulsion and syneresis. Therefore, the amount of serum recovered during cheese-making was related to WP addition level and to the presence of variants A or B or their combination. Cheese-making can be viewed as a dehydration process, and syneresis is the crucial method by which most of the moisture is lost from curd particles. In rennet-induced milk gels, the strong tendency of rennet gels to exhibit syneresis is related to extensive rearrangements of the network, which occur after gel formation (van Vliet and Walstra, 1985).

This study demonstrated that a higher cheese yield was obtained when $\beta$-LG variant $B$ was present per se, and it was not necessarily due to the presence of this variant and its association to a higher content of CN (Ng-Kwai-Hang et al., 1986) and fat (Aleandri et al., 1990), as shown by previous studies using milk. By making miniature cheese model systems, these 2 milk composition variables were kept constant, so it was demonstrated that the differences in milk coagulation properties, in connection with $\beta-\mathrm{LG}$, were due to the variants by themselves and not to the content of fat or $\mathrm{CN}$ in milk. Furthermore, the use of a model system allowed us to study the effect of $\beta$-LG variants present 


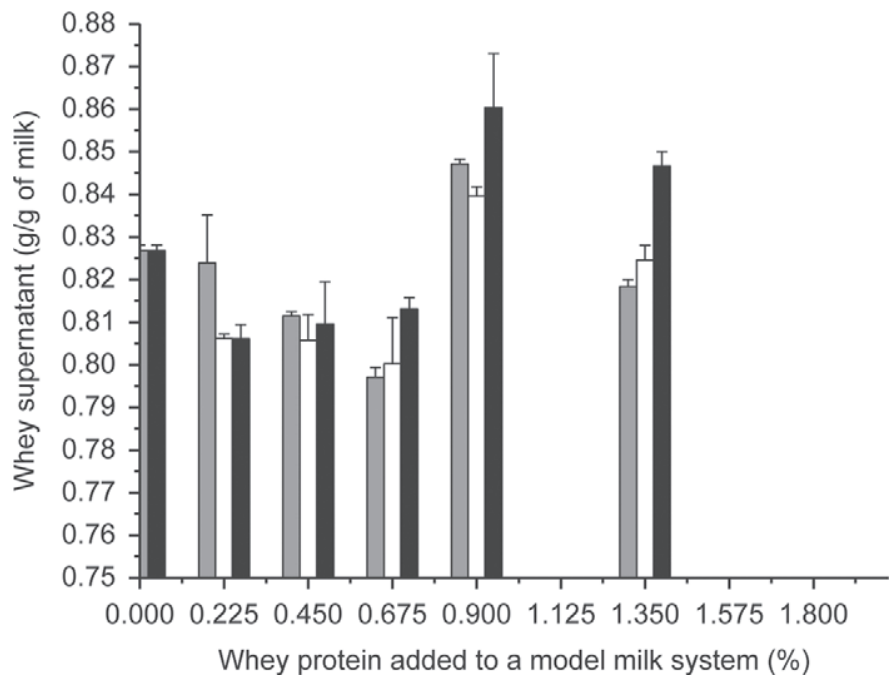

Figure 4. Syneresis of miniature model cheese as a function of whey protein addition $(\mathrm{n}=3)$. Model cheese containing $\beta$-LG B (white bars), $\beta-\mathrm{LG}$ A (gray bars), and $\beta$-LG A-B (black bars). Error bars represent the SD.

in milk on cheese-yield capacity without the need for adjustment for milk composition.

\section{ACKNOWLEDGMENTS}

This study was supported by the Mexican National Council of Science and Technology (Mexico City, Mexico) research grant No. 42340.

\section{REFERENCES}

Aaltonen, M. L., and V. Antila. 1987. Milk renneting properties and the genetics variants of proteins. Milchwissenschaft 42:490-492.

Aleandri, R., L. G. Buttazzoni, J. C. Schneider, A. Caroli, and R. Davoli. 1990. The effect of milk protein polymorphisms on milk components and cheese producing ability. J. Dairy Sci. 73:241255

Andrén, A. 2007. Influence of genetic milk protein variants on milk quality. J. Anim. Feed Sci. 16:143-150.

Bonfatti, V., G. Di Martino, A. Cecchinato, D. Vicario, and P. Carnier. 2010. Effects of $\beta$ - $\kappa$-casein (CSN2-CSN3) haplotypes and $\beta$-lactoglobulin (BLG) genotypes on milk production traits and detailed protein composition of individual milk of Simmental cows. J. Dairy Sci. 93:3797-3808.

Celik, S. 2003. $\beta$-Lactoglobulin genetic variants in brows swiss breed and its association with compositional properties and rennet time of milk. Int. Dairy J. 13:727-731.

Choi, J. W. 1996. Effects of genetic variants of $\kappa$-casein and $\beta$-lactoglobulin and heat treatments on cheese yielding capacity, cheese composition and coagulation properties. MS Thesis. McGill University, Ste. Anne-de-Bellevue, Québec, Canada.

Choi, J. W., and K. F. Ng-Kwai-Hang. 2002. Effects of genetics variants of $\kappa$-casein and $\beta$-lactoglobulin and heat treatment of milk on cheese and whey compositions. Asian-australas. J. Anim. Sci. 15:732-739.

Corredig, M., and D. G. Dalgleish. 1999. The mechanisms of heatinduced interaction of whey proteins with casein micelles in milk. Int. Dairy J. 9:233-236.

Glantz, M., H. Lindmark Mansson, H. Stalhammar, and M. Paulsson. 2011. Effect of polymorphisms in the leptin, leptin receptor, and acyl-coenzyme A:diacylglycerol acyltransferase 1 (DGAT1) genes and genetic polymorphism of milk proteins on cheese characteristics. J. Dairy Sci. 94:3295-3304.

Hallén, E., A. Wedholm, A. Andrén, and A. Lundén. 2008. Effect of $\beta$-casein, $\kappa$-casein and $\beta$-lactoglobulin genotypes on concentration of milk protein variants. J. Anim. Breed. Genet. 125:119-129.

Jan, H. D., and H. E. Swaisgood. 1990. Disulfide bond formation between thermally denatured $\beta$-lactoglobulin and $\kappa$-casein in casein micelles. J. Dairy Sci. 73:900-904.

Law, A. J. R., D. S. Horne, J. M. Banks, and J. Leaver. 1994. Heatinduced changes in the whey proteins and casein. Milchwissenschaft 49:125-129.

Lodes, A., J. Burchberger, I. Krause, J. Aumann, and H. Klostermeyer. 1996. The influence of genetic variants of milk proteins on the compositional and technological properties of milk. 2. Rennet coagulation time firmness of the rennet curd. Milchwissenschaft 51:543-547.

Mailliart, P., and B. Ribadeau-Dumas. 1988. Preparation of $\beta$-lactoglobulin and $\beta$-lactoglobulin free proteins from whey retentate by $\mathrm{NaCl}$ salting out at low $\mathrm{pH}$. J. Food Sci. 53:743-745.

Marziali, A. S., and K. F. Ng-Kwai-Hang. 1986. Relationships between milk protein polymorphism and cheese yielding capacity. J. Dairy Sci. 69:1193-1201.

Mclean, D. M., E. R. B. Graham, R. W. Ponsoni, and H. A. McKenzie. 1984. Effects of milk proteins genetic variants on milk yield and composition. J. Dairy Res. 51:531-546.

Melilli, C., J. M. Linch, S. Carpino, D. M. Barbano, G. Lecitra, and A. Cappa. 2002. An empirical method for prediction of cheese yield. J. Dairy Sci. 85:2699-2704.

Meza-Nieto, M. A., B. Vallejo-Córdoba, A. F. González-Córdova, L. Félix, and F. M. Goycoolea. 2007. Effect of $\beta$-lactoglobulin A and $\mathrm{B}$ whey protein variants on the rennet-induced gelation of skim milk gels in a model reconstituted skim milk system. J. Dairy Sci. 90:582-593.

Ng-Kwai-Hang, K. F. 1998. Genetic polymorphism of milk proteins: Relationships with production traits, milk composition and technological properties. Can. J. Anim. Sci. 78:131-147.

Ng-Kwai-Hang, K. F., and F. Grosclaude. 2002. Genetic polymorphism of milk proteins. Pages 405-455 in Advanced Dairy Chemistry-Volume 1: Proteins. P. E. Fox and P. L. H. McSweeney, ed. Kluwer Academic Publishers, New York, NY.

Ng-Kwai-Hang, K. F., J. F. Hayes, J. E. Moxley, and H. G. Monardes. 1984. Association of genetic variants of casein and serum proteins with milk, fat, and protein production by dairy cattle. J. Dairy Sci. 67:835-840.

Ng-Kwai-Hang, K. F., J. F. Hayes, J. E. Moxley, and H. G. Monardes. 1986. Relationships between milk protein polymorphisms and major milk constituents in Holstein-Friesian cows. J. Dairy Sci. 69:22-26.

Olguin-Arredondo, H., and B. Vallejo-Córdoba. 1999. Separation and determination of $\beta$-lactoglobulin variants A and B in cow's milk by capillary free zone electrophoresis. J. Capill. Electrophor. Microchip Technol. 6:145-149.

Pagnacco, G., and A. Caroli. 1987. Effect of casein and B-Lg genotypes on renneting properties of milk. J. Dairy Res. 54:479-485.

Reddy, I. M., and J. E. Kinsella. 1990. Interaction of $\beta$-lactoglobulin with $\kappa$-casein micelles as assessed by chymosin hydrolysis. Effects of added reagents. J. Agric. Food Chem. 38:311-318.

Schaar, J., B. Hansson, and H. Petterson. 1985. Effects of genetic variants of $\kappa$-casein and $\beta$-lactoglobulin on cheesemaking. J. Dairy Res. 52:429-437.

Tong, P. S., S. Vink, N. Y. Farkye, and J. F. Medrano. 1993. Effect of genetic variants of milk proteins on the yield of Cheddar cheese. Pages 179-187 in Cheese Yield and Factors Affecting Its Control. International Dairy Federation, Cork, Ireland.

van Vliet, T., and P. Walstra. 1985. Note on the shear modulus of rennet-induced milk gels. Neth. Milk Dairy J. 39:115-118.

Vasbinder, A. J., H. S. Rollema, and C. G. de Kruif. 2003. Impaired rennetability of heated milk; study of enzymatic hydrolysis and gelation kinetics. J. Dairy Sci. 86:1548-1555. 